\title{
Acute meningitis in rats is associated with decreased levels of miR132 and miR146a
}

\author{
MUBAREKA JAGOO, FANG HE, JING PENG, FEI YIN
}

Department of Pediatrics, Xiangya Hospital, Central South University, Changsha, PR China

\begin{abstract}
Introduction: The pathogenesis of bacterial meningitis due to Streptococcus pneumoniae is still unclear. Despite early treatment with antibiotics, its morbidity and mortality is still high.

Material and methods: Streptococcus pneumoniae induced rat meningitis models were taken and divided into 2 groups; control $(C)$ and meningitis $(M)$. Western blot was used to detect toll like receptor 4 (TLR4), tumor necrosis factor $\alpha(T N F-\alpha)$, interleukin $1 B(I L 1 B)$, nuclear factor $\kappa B(N F \kappa B)$ and real time polymerase chain reaction were used to detect the expression of $M i R 146 a$, miR132, respectively.

Results: We found that the expressions of TLR4, TNF- $\alpha, I L 1 B, N F \kappa B$ were all up-regulated in the acute stage of bacterial meningitis when compared to the control group. While for the post transcription factors, miR146a and miR132, the opposite was observed. They were down-regulated in the meningitis group.
\end{abstract}

Conclusions: miR146a and miR132 may take part in the pathogenesis of SP bacterial meningitis as well as the TLR4-NFKB-TNF- $\alpha / I L 1 B$ signal transduction pathway.

Key words: miR146a, miR132, bacterial meningitis, mechanism, inflammation.

(Centr Eur J Immunol 2014; 39 (3): 316-322)

\section{Introduction}

Bacterial meningitis, caused by Streptococcus pneumoniae, commonly leads to a significant number of deaths of approximately 700,000 to 1 million deaths per year globally [1], and is associated with the highest case fatality rate and neurological sequelae [2] even in patients being treated with appropriate antibiotics [3]. It is hence imperative to explore the pathogenesis mechanism of $S$. pneumoniae meningitis, in order to diagnose and give proper treatment to these children as early as possible [4]. It has been seen that the pathogenesis of bacterial meningitis is due to the host reaction with the capsule, cell wall and cytoplasm and also to the nucleus of the Gram-positive cocci [5-8]. During inflammatory responses, the toll like receptors (TLRs) recognize molecules broadly shared by streptococcus [7]. Stimulation of the TLRs due to the pathogen associated microbial patterns causes the initiation of the signaling cascade and activates transcription factors such as nuclear factor $\kappa \mathrm{B}(\mathrm{NF \kappa B})$ and induces some pro-inflammatory cytokines such as tumor necrosis factor $\alpha$ (TNF- $\alpha$ ) and IL1B [7]. These pro-inflammatory cytokines are considered to be related to acute meningitis [9]. While, identifying the post regulatory transcription factors that regulate the pro-inflammatory cytokines in a negative manner, can bring a novel understanding of the meningitis' pathogenesis.
miRNAs are a family of 18-24 single stranded nucleotide molecules which modulate the post-transcriptional expression of specific genes by controlling the stability and/or translation of target miRNAs [10]. Among them, miR146a and miR132, are present in elevated amounts in central nervous diseases $[11,12]$ acting as a bridge in linking both the immune and the neuronal functions in the case of an acute infection [13-15]. For example, miR146a was approved to be a pro-inflammatory marker in relation to IL1B [15] and was also seen to be down-regulated in numerous autoimmune diseases such as systemic lupus erythematosus [16]. The expression of miR132 is also decreased in CD4+ cells in the experimental autoimmune encephalitis model, suggesting a novel anti-inflammatory effect [17]. However, there are much more studies about these miRNAs in carcinogenesis and autoimmune diseases, making it hard to be found in infectious diseases.

Thus, in this research work, we studied the inflammatory markers of the signaling cascade from the receptor (TLR4) to the cytokines level (TNF- $\alpha$, IL1B), then targeting the nucleus at transcription steps for $\mathrm{NF \kappa B}$, and finally at the post transcriptional level - the miRNAs. Our aim was that these different levels could bring some light in the pathogenesis of acute $S$. pneumoniae bacterial meningitis. 


\section{Material and methods}

\section{Preparation of the animal model}

Twenty healthy Sprague Dawley (SD) rats, aged 3 weeks old, corresponding to 6 months in the human infant, were purchased from the Experimental Animal Centre of Xiangya Medical College at the Central South University. They were kept in germ free circumstances and allowed free access to standard pellet diet and water. Animals were cared for according to the guidelines of the China Council on animal care and all procedures carried out in accordance in the rules and regulations of the Institutional Animal Care and Use Committee of the Central South University. The animals were kept at specific room temperature of $20 \pm 2^{\circ} \mathrm{C}$ and humidity around $50-60 \%$. The animals were housed on an alternating 12-hour day/night cycle (lights on from 07:00 to 19:00). They were divided randomly into 2 groups: control $(C=10)$ and meningitis $(M=10)$. The mortality in each group was as follows: in the control group $\mathrm{C}=2$, and in the meningitis group $\mathrm{M}=4$.

\section{Bacterial strain}

Streptococcus pneumoniae serotype 3 was commercially bought from ATCC, American Type Culture Collection. (catalog number 6303).

\section{Solid media}

The bacteria were diluted in a dose of $0.2 \mathrm{mg} / \mathrm{ml}$, then cultured on solid blood agar medium. The blood agar was prepared according to the manufacturer's instructions, in brief: for each $45 \mathrm{~g}$ of solid agar base dissolved in $1000 \mathrm{ml}$ of distilled water, $50 \mathrm{ml}$ of fresh goat's blood must be added. In this experiment, $200 \mathrm{ml}$ of distilled water was mixed with 9 grams of solid agar base. The bottle was carefully sealed and sent for sterilization for a minimum of 4 hours. Later, $10 \mathrm{ml}$ of goat's blood was added to that mixture. Sterilized plates were used on which blood agar base, distilled water and goat's blood were poured onto. The plates were allowed to set overnight at 4 degrees. On the next day, a bacterial inoculator was used to spread the bacteria on the chocolate agar. On the solid blood agar, glistening colonies were formed after 18 hours, measuring about $1 \mathrm{~mm}$ each. The bacteria were diluted in a dose of $0.2 \mathrm{mg} / \mathrm{ml}$, then cultured on solid blood agar medium. The blood agar was prepared according to the manufacturer's instructions. On the solid blood agar, glistening colonies were formed after 18 hours, measuring about $1 \mathrm{~mm}$ each.

\section{Liquid media}

Streptococcus pneumoniae strains were grown on Trypticase soy agar (TSA II) supplemented with 5\% sheep's blood at $37^{\circ} \mathrm{C}$ in $5 \% \mathrm{CO}_{2}$ in liquid media. 4.6 grams of agar base was mixed in $200 \mathrm{ml}$ of distilled water. Yeast extract was added at a ratio of $0.2 \%$ in $1000 \mathrm{ml}$. It was sent for sterilization for at least 4 hours. 5-10\% of goat's blood was added; about $10 \mathrm{ml}$ of blood was added each time to the liquid media. The bacteria, bought commercially from ATCC, were dissolved in $500 \mathrm{ml}$ of normal saline $0.9 \% .2 \mathrm{ml}$ was removed each time and added to $7 \mathrm{ml}$ of the liquid media. The tubes along with a control, were centrifuged for at least 12 hours at $220 \mathrm{rpm}$ at 37 degrees. The growth was observed at 6,12 and 18 hours. The bacteria were grown on a serial of 4 subsequent cultures on liquid blood agar. With initial growth beginning in optimal conditions, autolysis usually begins within 18-24 hours, with colonies collapsing in the centers. They were examined after 15 hours for solid residues in the tubes. The red blood cells have been lysed and the cultures compared to the $0.5-5$ McFarland bacterial comparator.

In both solid and liquid media, the culture plates were carefully labeled as control, positive results and negative results.

\section{Animal model}

The 3-week-old healthy rats were weighed being on average $100 \mathrm{mg}$ each. They were all given chloral hydrate as anesthesia in a dose of $10 \%, 3 \mathrm{ml} / \mathrm{kg}$ intra-peritoneally and placed on the stereotactic frame. Intracisternal injection of $10^{6}$ colony-forming unit (CFU) S. pneumoniae in $10 \mu \mathrm{l}$ of $0.85 \%$ sterile saline. While the control group $(n=10)$ were injected with normal saline. The rats were allowed to recover in their cages with free access to food and water. Each group was carefully labeled. After 8 hours, the rats were observed for signs of meningism, piloerection, irritability, decreased spontaneous activity and a hunched position. $10 \mu \mathrm{l} \mathrm{CSF}$ was then obtained from the experimental $(n=10)$ and control $(n=10)$ rats by puncture of the cisterna magna, $5 \mu \mathrm{CSF}$ quantitatively cultured on TTC-nutrient agar for bacterial counts, another $5 \mu \mathrm{CSF}$ was used to count WBC. CSF leukocyte counts showed a significant difference between bacterial infected rats and those of the control group, $4582 \pm 16.31 \times 10^{6} / 1$ vs. $18.4 \pm 7.19 \times 10^{6} / 1(p<0.05)$, thus confirming the presence of meningitis in our rat model. Then, 3 of the infected rats were sacrificed under deep anesthesia by intra-peritoneal injection of chloral hydrate (10\%, $3 \mathrm{ml} / \mathrm{kg}$ ) $24 \mathrm{~h}$ after intracisternal injection of the S. pneumoniae inoculums and 4 of the control rats also included.

\section{Rat tissue preparation for ribonucleic acid isolation}

After decapitation, the brain of the animals of the other 3 infected group rats and remaining 4 controls, were immediately removed using RNAse free instruments and frozen in liquid nitrogen, stored at -80 degrees until further use.

\section{RNA isolation}

Total RNA was isolated using $1 \mathrm{ml}$ of Trizol Reagent (Invitrogen, Carlsbad CA, USA), $1 \mathrm{ml}$ for every $50 \mu \mathrm{g}$ of cortical tissue. After adding $0.2 \mathrm{ml}$ of chloroform, the 
aqueous phase was separated using Phase Lock tubes (Eppendorf, Hamburg, Germany). RNA was then precipitated using $0.5 \mathrm{ml}$ of isopropyl alcohol, washed twice with $75 \%$ ethanol and then dissolved in $50 \mu$ of nuclease free water. The optical density and concentration of each RNA group was measured using the nanodrop spectrophotometer at 260/280 nm (Ocean Optics, Dunedin, FL, U.S.A.).

\section{Quantitative PCR (qPCR)}

cDNA synthesis was performed from the RNA extracted from the different prepared astrocyte groups using the One Step PrimeScript ${ }^{\circledR}$ miR cDNA Synthesis Kit (TAKARA, Dalian, China) which includes three mixes $(2 \times$ miRNA Reaction Buffer Mix, miR PrimeScript ${ }^{\circledR}$ RT Enzyme Mix and $0.1 \%$ BSA). A $10-\mu l$ reaction contained $5 \mu \mathrm{l} 2 \times$ miR reaction buffer mix, $1 \mu \mathrm{lmiR}$ PrimeScript ${ }^{\circledR}$ RT enzyme mix and $1 \mu \mathrm{l} 0.1 \%$ BSA. RNA $100 \mathrm{pg}$, and DEPC-treated water up to $10 \mu \mathrm{l}$. The tubes were incubated at $37^{\circ} \mathrm{C}$ for $60 \mathrm{~min}$, the reaction was terminated at $85^{\circ} \mathrm{C}$ for $5 \mathrm{sec}$, and then the reaction was held at $4^{\circ} \mathrm{C}$. qPCR were performed using the SYBRR ${ }^{\circledR}$ Premix Ex Taq ${ }^{\mathrm{TM}}$ II (TAKARA, Dalian, China) kit in triplicate. The 10- $\mu$ l PCR contained the following: $5 \mu$ SYBRR $^{\circledR}$ Premix Ex Taq ${ }^{\mathrm{TM}}$ II, $0.4 \mu \mathrm{l}$ Uni-miR qPCR Primer, $2 \mu \mathrm{l} \mathrm{miR}$ specific primer for the tested miRNA (GeneCopoeia, USA), $1 \mu \mathrm{l}$ cDNA, and $1.6 \mu \mathrm{l}$ DEPC-treated water. The PCRs were incubated at $50^{\circ} \mathrm{C}$ for $2 \mathrm{~min}$ (UDG incubation) and $95^{\circ} \mathrm{C}$ for $30 \mathrm{~s}$, followed by 40 cycles of $95^{\circ} \mathrm{C}$ for $5 \mathrm{~s}$ and $60^{\circ} \mathrm{C}$ for $30 \mathrm{~s}$, followed by melting curve analysis from 65.0 to $95.0^{\circ} \mathrm{C}$ (increment $0.5^{\circ} \mathrm{C}, 0: 05$ ). The relative expression levels for brain-enriched miR132, and inflammation-related miR146a were calculated using the comparative CT method. miR146a and miR132 gene expression were analyzed using Takara miRNA assays, which were run on the Applied Biosystems 7900HT (Foster City, CA, U.S.A.) according to the instructions and manufacturer's set conditions. The relative quantitative level of miR146a and miR132 was determined using the 2-(AAC1) method from the software data analysis, provided by the manufacturer. Values were normalized.

\section{Protein extraction}

About $100 \mathrm{mg}$ of cerebral cortex tissue was crushed into powder in liquid nitrogen and $1 \mathrm{ml}$ of lysis buffer added $(970 \mu \mathrm{l}$ of NP40, $10 \mu \mathrm{l}$ of phenylmethylsulfonyl fluoride (PMSF), $10 \mu \mathrm{l}$ of cocktail (protease inhibitor) and $10 \mu \mathrm{l}$ of LY (phosphatase inhibitor). The mixture was vortexed, and incubated at $4^{\circ} \mathrm{C}$ in ice for one hour. The materials for protein extraction were bought from Amresco (Solon, U.S.A.). Centrifugation was done at $12,000 \mathrm{rpm}$ for $10 \mathrm{mi}-$ nutes at $4{ }^{\circ} \mathrm{C}$. The nucleoproteins were extracted for the western blot of $\mathrm{NF \kappa B}$, which were operated followed by the instruction manual of NE-PER (R) Nuclear and Cytoplasmic Extraction kit (Pierce, U.S.A.).

\section{Western blot technique to detect TLR4, TNF- $\alpha$, IL1B, NF $\kappa$ B}

Different concentrations of sodium dodecyl sulphate-polyacrylamide gels were made overnight according to the molecular weight of the protein targeted. A total of $30 \mu \mathrm{g}$ of protein was loaded in each well. The polyvinylidene fluoride (PDVF) membrane was blocked with milk, was incubated overnight at $4^{\circ} \mathrm{C}$ with specific primary antibodies against each targeted protein at specified concentrations, then incubated again with the corresponding second antibody as shown in Table 1. $\beta$-actin was used each time as a loading control. Enhanced chemiluminescence (ECL) detection system was used to visualize each reaction. Autography detected the signals on the blots. The film was digitally scanned and then quantified using FluorChem software, (Alpha Innotech, U.S.A.). Quantification was performed by densitometry of Western blot bands using the Image J software.

\section{Statistical analysis}

All experimental data were expressed as mean \pm SD. Student $t$ test using SPSS software (version 13.0 SPSS) was used to compare the difference between the 2 groups. Statistical significance was defined as $p$ less than 0.05 .

Table 1. The different concentration ratios for the respective primary and secondary antibodies in the following inflammatory markers

\begin{tabular}{|c|c|c|c|c|}
\hline Protein & $\begin{array}{c}\text { Molecular } \\
\text { weight/KDA }\end{array}$ & $\begin{array}{c}\text { Gel } \\
\text { concentration }\end{array}$ & First antibody & Second antibody \\
\hline TLR4 & 93 & $8 \%$ & $\begin{array}{l}\text { monoclonal mouse antibodies (Abcam } \\
\text { Ltd. Hong Kong, ab22048) } 1: 50\end{array}$ & $\begin{array}{c}\text { goat anti mouse IgG (Jackson, Immuno Research, } \\
\text { U.S.A.) at } 1: 10000\end{array}$ \\
\hline IL1B & 31 & $10 \%$ & $\begin{array}{l}\text { polyclonal antibodies (Novus Biologicals, } \\
\text { Littenton, CO, U.S.A.) at } 1: 500\end{array}$ & $\begin{array}{c}\text { horseradish peroxidase (HRP) conjugated } \\
\text { sheep anti-rabbit IgG (Amersham Biosciences, } \\
\text { Piscataway, Nj, U.S.A.) } 1: 10000\end{array}$ \\
\hline TNF- $\alpha$ & 17 & $10 \%$ & $\begin{array}{l}\text { monoclonal mouse antibodies (Abcam } \\
\text { Ltd. Hong Kong, ab22048) } 1: 1000\end{array}$ & $\begin{array}{c}\text { goat anti mouse IgG (Jackson, Immuno Research, } \\
\text { U.S.A.) at } 1: 5000\end{array}$ \\
\hline $\mathrm{NF} \kappa \mathrm{B}$ & 64 & $10 \%$ & $\begin{array}{l}\text { polyclonal antibodies (Abcam, Hong } \\
\text { Kong) } 1: 500\end{array}$ & $\begin{array}{c}\text { horseradish peroxidase (HRP) conjugated } \\
\text { sheep anti-rabbit IgG (Amersham Biosciences, } \\
\text { Piscataway, Nj, U.S.A.) } 1: 10000\end{array}$ \\
\hline
\end{tabular}




\section{Results}

In Fig. 1 to Fig. 4, the upper bands demonstrate the different immunoblots for TLR4, IL1B, TNF- $\alpha$ and NFKB, placed above $\beta$-actin, which was used as control throughout the experiment.

\section{TLR4}

Using the Western Blot method, TLR4, originating from the surface receptors of dendritic cells, showed an escalation in the meningitis group $($ mean $=33.24 \pm 0.70)$ as compared to the control group (mean $=18.01 \pm 1.51$ ), as shown in Fig 1. The results were compared each time with $\beta$-actin as control. To get the different expressions of TLR4, 30 nanograms of extracted protein was placed in the protein wells in Western Blot. An $8 \%$ gel was used. The primary antibody and secondary antibody are at a concentration of $1: 150$ and $1: 10000$, respectively.

\section{IL1B}

IL1B is an inflammatory cytokine found in the early stages of inflammation. It has a molecular weight of $64 \mathrm{KDA}$. Hence, a $10 \%$ sodium dodecyl gel was used. The concentration of the primary and the secondary antibodies were $1: 500$ and $1: 10,000$, respectively. In the meningitis group (mean $=35.04 \pm 0.75$ ), the expression of IL1B was upregulated as compared to the control group $($ mean $=11.81 \pm 0.67)$.

\section{Tumor necrosis factor $\alpha$}

TNF- $\alpha$, the primary antibody was monoclonal mouse antibody at a concentration of $1: 1000$ and the second-
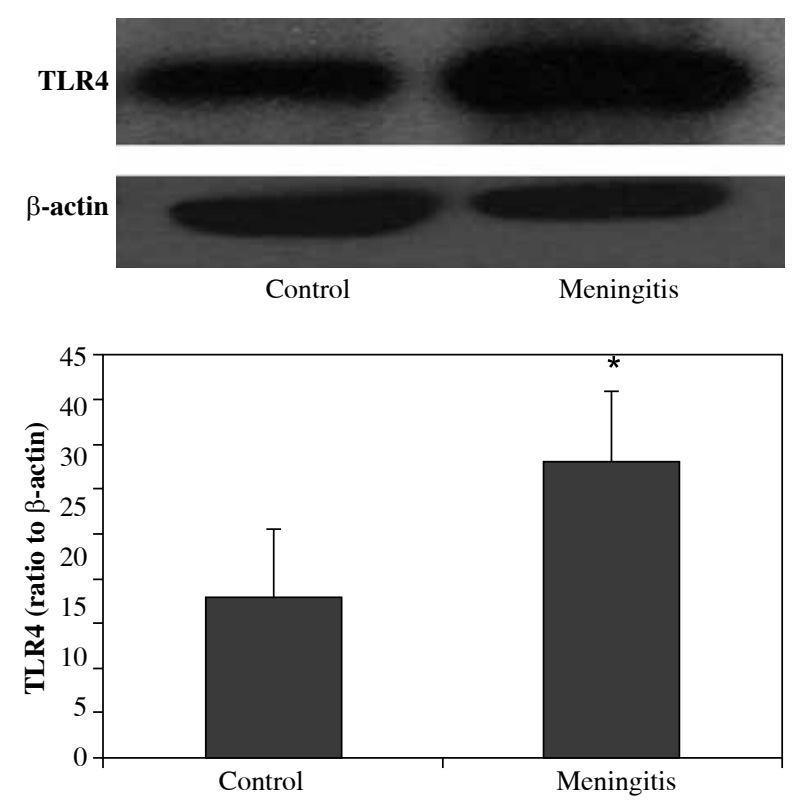

$* p<0.05$ on comparing with Control

Fig. 1. The expression of TLR4 ary antibody was at a concentration of 1: 5000. Being of molecular weight of $17 \mathrm{KDA}$, a $10 \%$ sodium dodecyl gel was used. Fig. 3 shows that in the control group, when only normal saline has been injected, this had a result of mean $=21.31 \pm 3.40$, compared to the meningitis group with a $($ mean $=34.37 \pm 1.26)$.

\section{Nuclear factor $\kappa \mathbf{B}$}

$\mathrm{NF} \kappa \mathrm{B}$ is found in the nucleus of cells enabling transcription, which showed that if the $\mathrm{NF} \kappa \mathrm{B}$ in the nucleus is increased, it would be up-regulated. The result showed a rise in the level of $N F \kappa B$ in the meningitis group. The Fig. 4 shows the expression of NFKB being as follows: control group $($ mean $=10.71 \pm 0.57)$, meningitis group $($ mean $=32.77 \pm 1.73)$. The results tally with the other inflammatory markers described earlier, where an increased expression is seen in the meningitis group.

\section{Real time PCR results of miR146a}

The miRNA expression of miR146a was detected using the SYBREX (Biorad) protocol which is as follows: $95.0^{\circ} \mathrm{C}$ for $30 \mathrm{~min}, 95.0^{\circ} \mathrm{C}$ for $0.05 \mathrm{~s}, 60.0^{\circ} \mathrm{C}$ for $30 \mathrm{~min}$. The melt curve was set at a temperature of $65.0^{\circ} \mathrm{C}$ to $95.0^{\circ} \mathrm{C}$ with an increment of $0.5^{\circ} \mathrm{C}$ at $0.05 \mathrm{~s}$. Real time PCR results showed a completely different result as compared to the other inflammatory markers. A significant down-regulation of miR146a in the meningitis group (mean $=0.19$ $\pm 0.04)$ compared to the control group $($ mean $=0.78 \pm 0.32)$ was noted in Fig. 5.
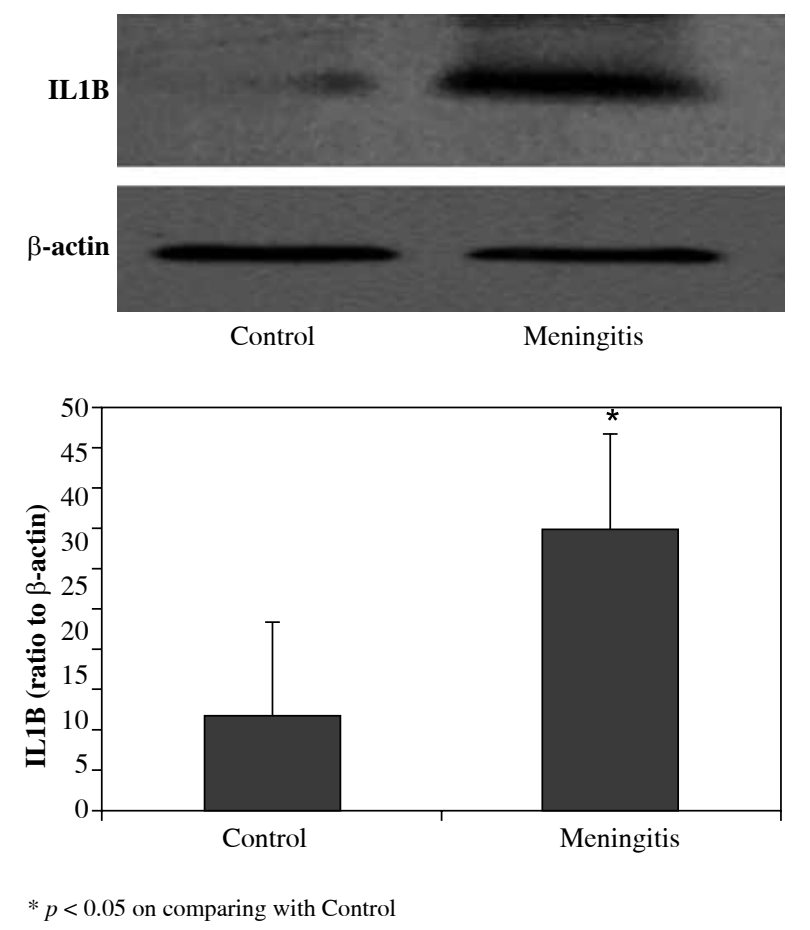

Fig. 2. The expression of IL1B 


\section{Real time PCR results of miR132}

The miRNA expression of miR132 was detected using the same SYBREX (Biorad) protocol as for miR146a. Real time PCR results showed a completely different result as compared to the other inflammatory markers. A significant down-regulation of miR146a in the meningitis group (mean $=0.19 \pm 0.04$ ) compared to the control group (mean $=0.78 \pm 0.32$ ) was noted in Fig. 6 .

\section{Discussion}

Bacterial meningitis no doubt leads to significant mortality and disability if left untreated early. There are many retrospective and prospective studies showing the importance of preventing major adverse outcomes in the early administration of antibiotics [18, 19]. But still, it seems that antibiotics alone, are not sufficient to approach its serious consequences. The final outcome and prognosis in acute bacterial meningitis depend mainly on the inflammatory response in the subarachnoid space [9].

It has been found that TLR4, NFKB and TNF- $\alpha$, IL1B form a part in the pro-inflammation signal transduction cascade of meningitis [8]. Toll like receptors could initiate specific immune responses due to their pattern recognition receptors which allow them to detect both self and non-self-antigens [20] and then recruit the myeloid differentiation primary response gene (MyD) 88 , which in turn mediates the degradation of $\mathrm{NF \kappa B}$ inhibitor $\mathrm{IKb}$. Activated
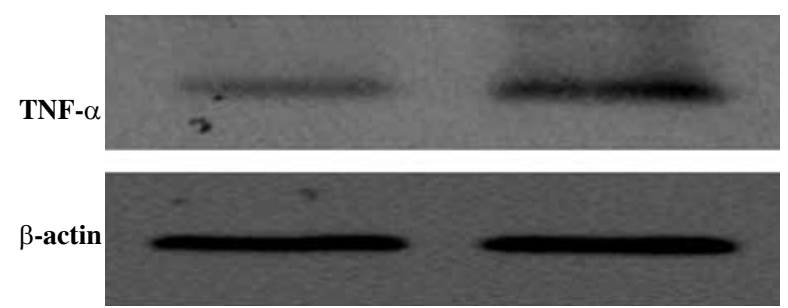

Control Meningitis

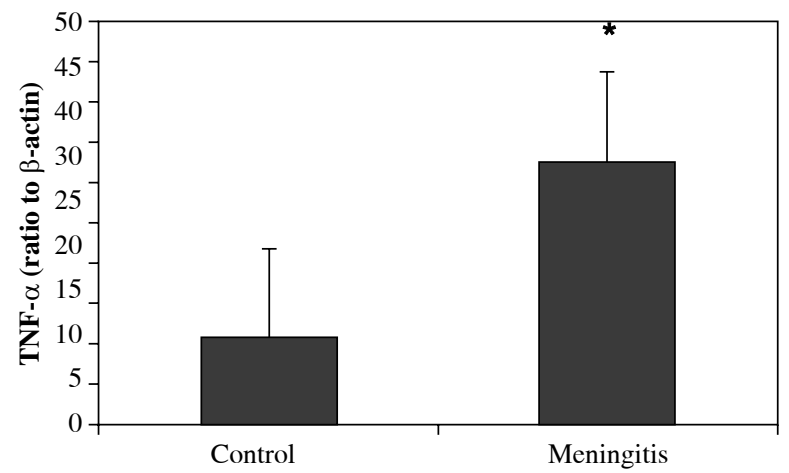

" $p<0.05$, on comparing with the Control

Fig. 3. The expression of TNF- $\alpha$
$\mathrm{NF} \kappa \mathrm{B}$ migrates to the nucleus and up-regulates the pro-inflammatory cytokines like TNF- $\alpha$ and IL1B, which trigger a cascade of inflammatory mediators including other cytokines, chemokines, arachidonic acid metabolites, reactive nitrogen and oxygen intermediates and proteases, and then cause blood brain barrier damage, hence resulting in brain edema [21]. It is hinted that TLR4-NFאB-TNF- $\alpha$ / IL1B pathway could be a potential treatment strategy for regulating the inflammation in meningitis patients, which would decrease the brain edema and reduce the neology squeals/neurological sequelae. In our study, the expression of the receptor (TLR4), nucleus for transcription (NFkB) and inflammatory cytokines (TNF- $\alpha$ and IL1B) shoot up in the acute stage of bacterial meningitis compared to the control, which supported that TLR4- NFkB-TNF- $\alpha$ /IL1B pathway is important in the regulation of the inflammatory process in S. pneumoniae bacterial meningitis. However, it is not completely known how to regulate this pathway.

As to the anti-inflammatory process, some miRNAs, especially for the miR146a, are considered to participate as the post-transcriptional factor. It could target TAB2, IRAK1 and TRAF6, thereby preventing NFKB activation [22]. The latest studies found that miR146a inhibited endothelial activation by dampening the activation of pro-inflammatory transcriptional programs, including AP-1 and MAPK/EGR pathways, likely through regulation of IL1B signaling pathway adaptor proteins [19]. As we know, endothelial activation would contribute to blood brain barrier disruption and would lead to brain edema resulting in the
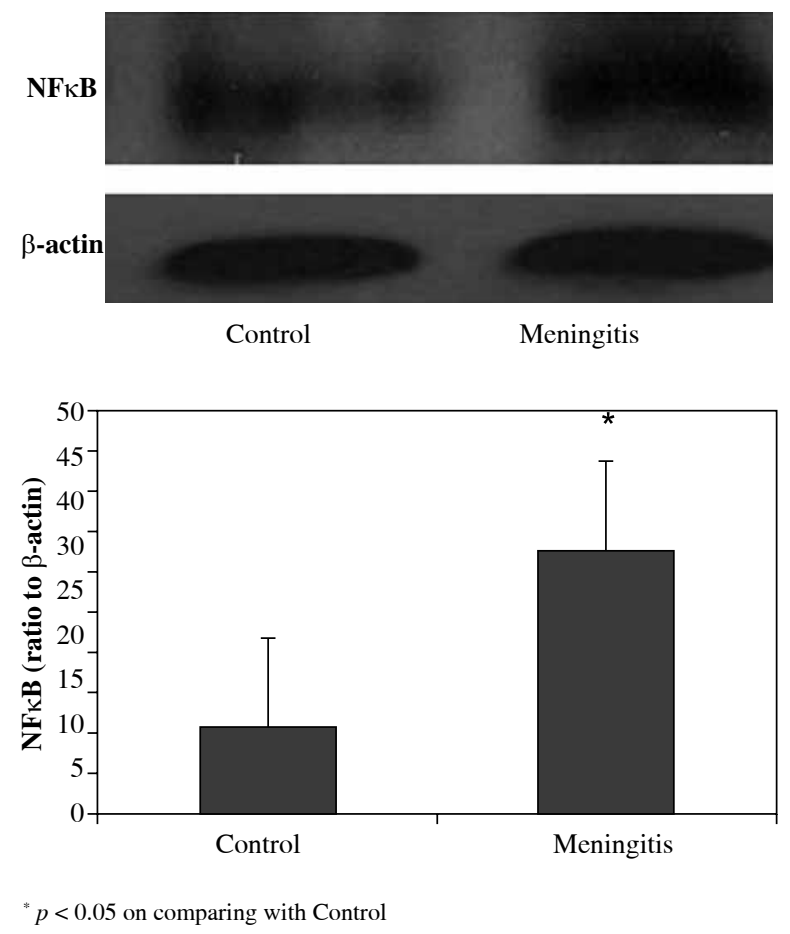

Fig. 4. The expression of NFKB 


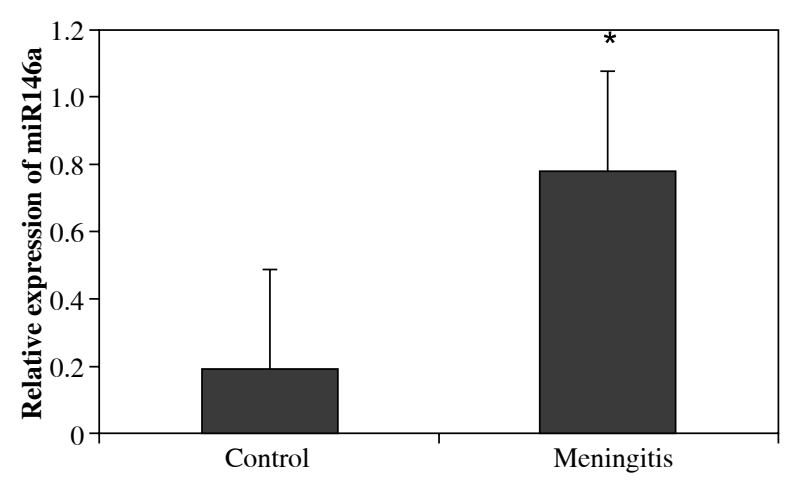

Fig. 5. The relative expression of miR146a

long sequelae of meningitis. Thus, it would be hypothesized that miR146a negatively regulates inflammation in meningitis. miR132 is another post transcription factor which is brain enriched and also modulates inflammation. Its transcription is stimulated by LPS and up-regulated at an early stage of HCMV infection, and it has been approved to be involved in the regulation of CNS inflammation induced by A. cantonensis [23] and of ocular infection induced by herpes simplex virus [24]. Thus, we speculated that both miR146a and miR132 could be considered as the possible anti-inflammatory genes in S. pneumoniae meningitis. There is still no research being done about the different pathogenic steps of miR146a and miR132 in the $S$. pneumoniae animal model. In our study, we found that, corresponding with the activation of TLR4- NFKBTNF- $\alpha /$ IL1B pathway in acute $S$. pneumoniae meningitis, the results of real-time PCR detected significant down-regulation of both miR146a and miR132 in the same animal model, putting these miRNAs as potential candidates to understand the pathogenesis of $S$. pneumoniae meningitis at the posttranscriptional level.

\section{Conclusions}

We are the first to reveal that the noncoding small miRNA, miR146a and miR132 are novel regulators of inflammation of $S$. pneumoniae meningitis. The modulation of the anti-inflammatory process mediated by these miRNAs was likely to be related to the TLR4-NFKBTNF- $\alpha /$ IL1B signal transduction pathway. However, further loss-of-function and gain-of-function studies of these miRNAs should be implemented in order to clearly understand its mechanisms in regulating gene expression and to evaluate its potential as a biomarker or therapeutic target in S. pneumoniae meningitis diseases.

This work was kindly supported by the National Natural Science Foundation of China (NO. 81301031). We would also like to thank the National Laboratory of Medi-

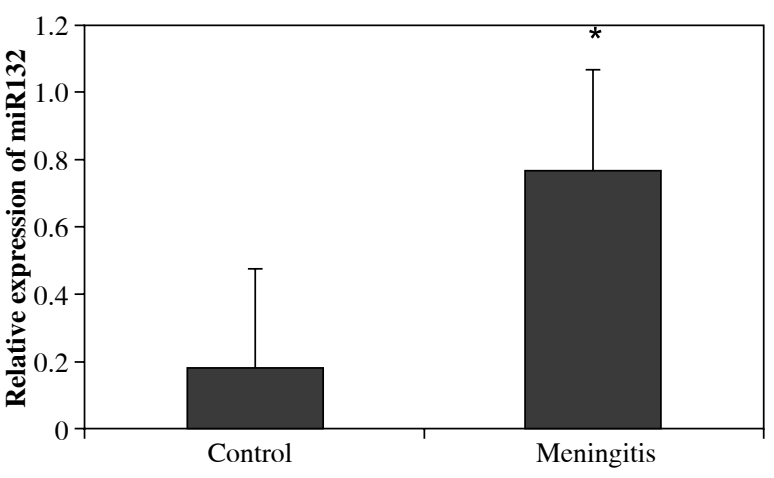

Fig. 6. The relative expression of miR132

cal Genetics of China for providing the experimental conditions to carry out this work. All coauthors have been substantively involved in the study and/or the preparation of the manuscript and do not have any conflict of interest.

\section{References}

1. Raymond F, Boucher N, Allary R, et al. (2013): Serotyping of Streptococcus pneumoniae Based on Capsular Genes Polymorphisms. PLoS One 8: p. e76197.

2. Rückinger S, von Kries R, Siedler A, van der Linden M (2009): Association of serotype of Streptococcus pneumoniae with risk of severe and fatal outcome. Pediatr Infect Dis J 28: 118-122.

3. Papavasileiou K, Papavasileiou E, Tzanakaki G, et al. (2011): Acute bacterial meningitis cases diagnosed by culture and PCR in a children's hospital throughout a 9-Year period (2000-2008) in Athens, Greece. Mol Diagn Ther 15: 109-113.

4. Kulik DM, Uleryk EM, Maguire JL (2013): Does this child have bacterial meningitis? A systematic review of clinical prediction rules for children with suspected bacterial meningitis. J Emerg Med 45: 508-519.

5. Koedel U, Klein M, Pfister HW (2010): New understandings on the pathophysiology of bacterial meningitis. Curr Opin Infect Dis 23: 217-223.

6. Koedel U, Scheld WM, Pfister HW (2002): Pathogenesis and pathophysiology of pneumococcal meningitis. Lancet Infect Dis 2: 721-736.

7. Klein M, Obermaier B, Angele B, et al. (2008): Innate immunity to pneumococcal infection of the central nervous system depends on toll-like receptor (TLR) 2 and TLR4. J Infect Dis 198: 1028-1036.

8. Tuomanen EI (2000): Pathogenesis of pneumococcal inflammation: otitis media. Vaccine 19 Suppl 1: S38-S40.

9. Mook-Kanamori BB, Geldhoff M, van der Poll T, van de Beek D (2011): Pathogenesis and pathophysiology of pneumococcal meningitis. Clin Microbiol Rev 24: 557-591.

10. Petri R, Malmevik J, Fasching L, et al. (2014): miRNAs in brain development. Exp Cell Res 321: 84-89.

11. Li YY, Cui JG, Dua P, et al. (2011): Differential expression of miRNA-146a-regulated inflammatory genes in human primary neural, astroglial and microglial cells. Neurosci Lett 499: 109-113.

12. Pogue AI, Li YY, Cui JG, et al. (2009): Characterization of an NF-kappaB-regulated, miRNA-146a-mediated down-regula- 
tion of complement factor $\mathrm{H}(\mathrm{CFH})$ in metal-sulfate-stressed human brain cells. J Inorg Biochem 103: 1591-1595.

13. Wanet A, Tacheny A, Arnould T, Renard P (2012): miR212/132 expression and functions: within and beyond the neuronal compartment. Nucleic Acids Res 40: 4742-4753.

14. Quinn SR, O'Neill LA (2011): A trio of microRNAs that control Toll-like receptor signalling. Int Immunol 23: 421-425.

15. Iyer A, Zurolo E, Prabowo A, et al. (2012): MicroRNA-146a: a key regulator of astrocyte-mediated inflammatory response. PLoS One 7: e44789.

16. Tang Y, Luo X, Cui H, et al. (2009): MicroRNA-146A contributes to abnormal activation of the type I interferon pathway in human lupus by targeting the key signaling proteins. Arthritis Rheum 60: 1065-1075.

17. Hanieh H, Alzahrani A (2013): MicroRNA-132 suppresses autoimmune encephalomyelitis by inducing cholinergic anti-inflammation: a new Ahr-based exploration. Eur J Immunol 43: 2771-2782.

18. Proulx N, Fréchette D, Toye B, et al. (2005): Delays in the administration of antibiotics are associated with mortality from adult acute bacterial meningitis. QJM 98: 291-298.

19. Auburtin M, Wolff M, Charpentier J, et al. (2006): Detrimental role of delayed antibiotic administration and penicillin-nonsusceptible strains in adult intensive care unit patients with pneumococcal meningitis: the PNEUMOREA prospective multicenter study. Crit Care Med 34: 2758-2765.

20. Maiolini A, Carlson R, Tipold A (2012): Toll-like receptors 4 and 9 are responsible for the maintenance of the inflammatory reaction in canine steroid-responsive meningitis-arteritis, a large animal model for neutrophilic meningitis. J Neuroinflammation 9: 226.

21. Saukkonen K, Sande S, Cioffe C, et al. (1990): The role of cytokines in the generation of inflammation and tissue damage in experimental gram-positive meningitis. J Exp Med 171: 439-448.

22. Nahid MA, Satoh M, Chan EK (2011): Mechanistic role of microRNA-146a in endotoxin-induced differential cross-regulation of TLR signaling. J Immunol 186: 1723-1734.

23. Yu L, Liao Q, Chen X, et al. (2014): Dynamic expression of miR-132, miR-212, and miR-146 in the brain of different hosts infected with Angiostrongylus cantonensis. Parasitol Res Parasitol Res 2014; 113: 91-99.

24. Mulik S, Xu J, Reddy PB, et al. (2012): Role of miR-132 in angiogenesis after ocular infection with herpes simplex virus. Am J Pathol 181: 525-534. 